\title{
Horizontal transmission and subsequent development of Amblyospora californica (Microsporida: Amblyosporidae) in the intermediate and definitive hosts
}

\author{
James J. Becnel \\ US Department of Agriculture, Agricultural Research Service, Medical and Veterinary Entomology Research Laboratory,
} PO Box 14565, Gainesville, Florida 32604, USA

\begin{abstract}
Amblyospora californica (type species) was transmitted horizontally by feeding meiospores from larvae of Culex tarsalis (definutive host) to the copepod Macrocyclops albidus (a new intermediate host) and, conversely, by feeding spores produced in adult copepods to larval mosquitoes. Key features of the developmental sequence resulting from the 2 transmissions were demonstrated with both light and electron microscopy. Development in the copepod started with uninucleate sporoplasms from the ingested meiospores, included merogony by binary division of uninucleate meronts, sporogony by binary (usually) or multiple division and production of uninucleate-lanceolate spores within individual envelopes. Development in the mosquito began with uninucleate sporoplasms from the ingested lanceolate spores, included a first merogony (gametogony), plasmogamy, nuclear association, a second merogony and disporous sporulation with the production of Nosema-like spores in the adult female. This female represents a parental generation that transmits the infection transovarially (vertically) to male and female progeny. By combining results of this study with published data on development in filial generation mosquitoes, it was possible to outline the complete life cycle.
\end{abstract}

\section{INTRODUCTION}

The microsporidium currently known as Amblyospora californica was first described parasitizing the fat body of Culex tarsalis larvae by Kellen \& Lipa (1960). Based upon sporonts that gave rise to 8 spores, they originally assigned this species to the genus Thelohania. Later, a microsporidium was found infecting oenocytes of adult C. tarsalis females which was described as a new species Nosema lunatum (Kellen et al. 1967).

Working with a species which they identified as Thelohania legeri, Hazard \& Weiser (1968) found a type of dimorphism that was new for the microsporidia and was characterized by 2 sporulation sequences (separated in time and host stage), the first giving rise to the second. More specifically, they proved that binucleate spores formed in female adult anopheline mosquitoes were responsible for infections in progeny. The sporu- lation sequence in infected male progeny ended with spores in groups of 8 (meiospores). Because of similarities between $T$ legeri and the microsporidium from Culex tarsalis, they suggested that $T$. californica and Nosema lunatum may also represent a single species. In 1975, Hazard \& Oldacre combined these 2 nominal species as Amblyospora californica and designated it as the type species of the genus Amblyospora.

Still unknown was the role of the meiospores in the life cycle of Amblyospora californica, as all attempts to infect mosquito larvae per os (horizontal) failed (Kellen \& Lipa 1960, Kellen \& Wills 1962a, b). Hazard et al. (1979) and Andreadis \& Hall (1979) postulated that the meiospores produced in an Amblyospora sp. may function to infect an 'alternate' host prior to reinfecting the 'primary' mosquito host. This suggestion was recently substantiated with the discovery that the meiospores of A. dyxenoides are infectious to a copepod intermediate host (Sweeney et al. 1985). 
Two developmental sequences of Amblyospora californica in Culex tarsalis are known to follow transovarial transmission - one that ends with binucleate spores in the female adult and a second that ends with meiospores in male larvae (Kellen \& Lipa 1960, Kellen \& Wills 1962b, Kudo \& Daniels 1963, Lipa \& Bartkowski 1981, Chen 1988). Two additional developmental sequences that are the result of separate horizontal transmission events, one in the type intermediate host Mesocyclops leukarti and another in the mosquito host, have been reported for A. californica but with few details (Sweeney et al. 1985 \& 1988, Becnel 1986, Chen 1988). This investigation describes these 2 developmental sequences, one in a new intermediate host, Macrocyclops albidus, and the other in C. tarsalis. With this new information, the life cycle of A. californica is completed which facilitates the comparison of Amblyospora with other heterosporous genera of microsporidia from mosquitoes.

\section{MATERIALS AND METHODS}

A healthy colony of Culex tarsalis and one infected with Amblyospora californica were obtained from Dr Monica Asman of Berkeley, California (USA). Both colonies originated from the Bakersfield area. The parasite was maintained through transovarial transmission, male progeny dying as a result of the infection. The healthy colony provided males both to maintain the infected colony and to produce larvae for horizontal transmission tests. The copepod Macrocyclops albidus was collected from woodland pools near Gainesville, Florida. A culture of the copepod Acanthocyclops vernalis was obtained from Dr T. G. Andreadis of New Haven, Connecticut

Mosquito to copepod transmission. Adult copepods were separated into groups of ca 100 individuals in $250 \mathrm{ml}$ of filtered $(0.2 \mu \mathrm{m})$ field water. The water containing each group was inoculated with meiospores (from male larvae of Culex tarsalis) for a final concentration of $1 \times 10^{4}$ spores $\mathrm{ml}^{-1}$ and held at room temperature. Control groups were handled in a similar manner but without the addition of meiospores.

Copepod to mosquito transmission. Spores experimentally produced in Macrocyclops albidus, as described above, were used as inoculum. Twenty-five first or second instar mosquitoes were placed into $60 \times 15 \mathrm{~mm}$ Petri dishes containing $20 \mathrm{ml}$ of filtered field water with 3 to 6 ground or minced infected copepods. A small amount of food was added to each dish and larvae were held for $24 \mathrm{~h}$ at room temperature. Larvae were then transferred to laboratory pans that contained $500 \mathrm{ml}$ water and reared according to normal protocol. Control groups were handled in a similar manner but without the addition of spores

Infected individuals from the transmission experiments were observed daily with Giemsa-stained smears to follow the progression of the disease. Heidenhain-stained paraffin sections, Lacto-AcetoOrcein squash preparations (Hazard et al. 1984), and tissues for ultrastructural studies were processed from larvae, pupae and adults based upon these observations. Infected tissues used in the EM studies were fixed for $2.5 \mathrm{~h}$ at room temperature in $2.5 \%(\mathrm{v} / \mathrm{v})$ glutaraldehyde in $0.1 \mathrm{M}$ cacodylate buffer $(\mathrm{pH} 7.4)$ containing $0.1 \% \mathrm{CaCl}_{2}$ and postfixed in $1 \%$ aqueous $\mathrm{OsO}_{4}(\mathrm{w} / \mathrm{v})$. These tissues were dehydrated though an ascending ethanol and acetone series and embedded in Epon-Araldite. Thin-sections were poststained with methanolic uranyl acetate followed by lead citrate.

\section{RESULTS}

The life cycle of Amblyospora californica included 2 successive spore to spore developmental sequences as a result of horizontal transmission. One sequence began with sporoplasms from ingested meiospores and ended with uninucleate, lanceolate spores in the copepod intermediate host. The other, in mosquitoes, began with sporoplasms from uninucleate, lanceolate spores ingested by the larvae and ended with binucleate spores in the adult female.

\section{Development in Macrocyclops albidus}

Attempts to infect Acanthocyclops vernalis were unsuccessful. Female copepods of Macrocyclops albidus exposed to meiospores of Amblyospora californica developed infections restricted to the ovaries (Fig. 7). Egg sacks were never observed on infected female adults. Rupture of the ovaries often resulted in the release of spores into the hemocoel giving the false impression of systemic infections. The progression of the infection was remarkably synchronized, with merogony abruptly giving way to sporogony and then sporogenesis.

Merogony. Meronts were round to oval in form and merogony was an alternation of large and small cells, the single, compact nucleus increasing in size in preparation for division (Fig. 1). They were bound by a simple plasmalemma that was normally in direct contact with the hyaloplasm of the host cell (Fig. 8). Spindle plaques were common on the nuclear envelope (Fig. 8) indicative of prolific reproduction that was by binary divisions (Figs. 2, 3, 9). Merogony was apparently the main method of multiplication of the developmental sequence in the copepod. 

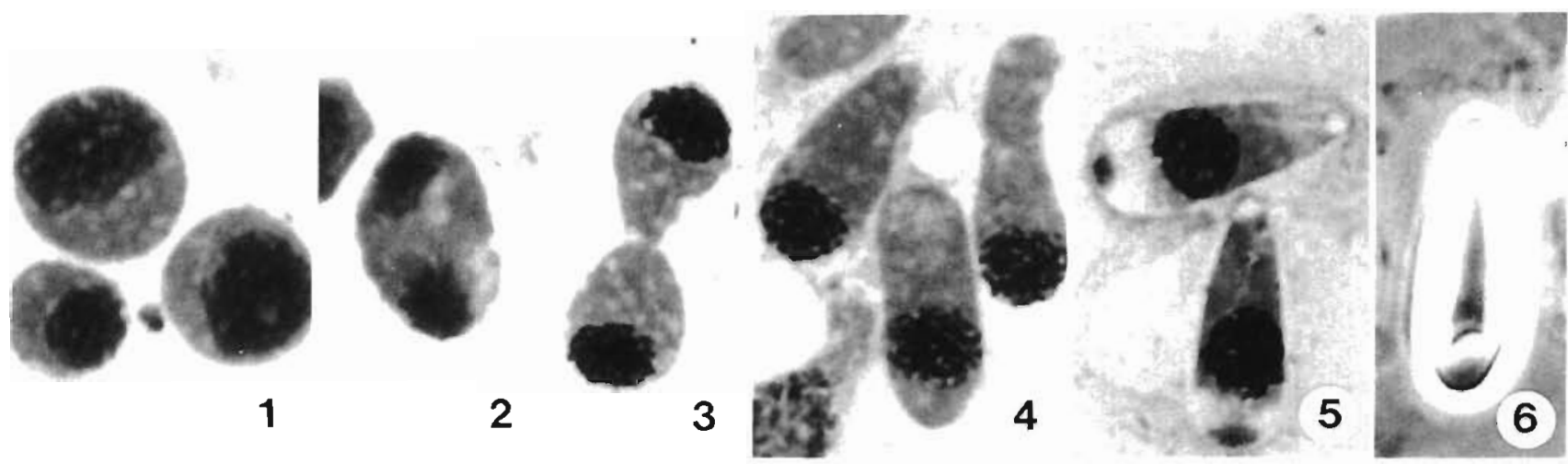

Figs. 1 to 6. Amblyospora californica. Developmental stages in ovaries of the copepod intermediate host Macrocyclops albidus. Giemsa-stained and $\times 2000$ except Fig. 6 which is live (phase contrast). Fig. 1. Meronts, the larger 2 apparently preparing for division. Fig. 2. Meront undergoing binary division. Fig. 3. Dividing stage, cytokinesis nearing completion. Fig. 4. Early sporoblasts. Fig. 5. Two late sporoblasts. Fig. 6. A mature uninucleate spore

Transition from merogony to sporogony. The final products of merogony transformed directly into uninucleate sporonts. Cells considered transitional between merogony and sporogony were identified by 2 areas of specialization at the host-parasite interface (Fig. 10). One of these involved the plasmalemma of the parasite and membranes of the host cell. This interface was composed of regularly spaced crossbars running at right angles to the cell surface and resembled a type of cell junction referred to by cytologists as a septate desmosome (Fig. 10a). The other area was a thickening beneath the plasmalemma as electrondense material accumulated (Fig. 10b). This 'thickening' of the plasmalemma has commonly been used as a marker for identifying sporonts together with an increase in the amount of rough endoplasmic reticulum (Fig. 10).

Sporogony. Sporonts typically were pyriform with the nucleus located at the broader pole of the cell (Figs. 4, 11). They were distinguished by a thickened plasmalemma and the formation of a delicate interfacial envelope as a separate unit membrane exterior to the plasmalemma (Fig. 11a). The envelope developed into 'blisters' on the plasmalemma and initially contained tubular material (Fig. 11b). Sporogony usually consisted of one binary division but occasionally sporogonial plasmodia were produced that underwent multiple fission via rosette formation (Fig. 12). Cytokinesis resulted in sporoblasts (Fig. 5) each within a vesicle formed by a coalescence of the 'blisters' of the interfacial envelope (Fig. 13). As development proceeded, the tubules within the episporontal space (Fig. 13) disintegrated, leaving small amounts of amorphous material that eventually disappeared (Fig. 14).

Spore. Uninucleate spores were formed after 8 to $10 \mathrm{~d}$ of development. The mature spores were lanceolate, often curved (Fig. 6) and measured 13.8 (range
12.6 to 15.0$) \times 4.0$ (range 3.7 to 4.3 ) $\mu \mathrm{m}$ (fresh, $\mathrm{n}=32$ ). The spore was distinguished by an extensive polaroplast that was divided into chambers by a helical arrangement of septa (Fig. 14). The polar filament was isofilar and made 10 to 11 turns in the region of the nucleus and posterior end of the polaroplast. The spore wall was thin with the endospore thicker than the exospore.

\section{Development in Culex tarsalis}

First merogony (often called micronuclear merogony). Uninucleate, lanceolate spores of Amblyospora californica (formed in the copepod) were infectious to male and female mosquito larvae when ingested. In some unknown manner, uninucleate stages (sporoplasms?) of the parasite entered host oenocytes where they apparently remained dormant until pupation when multiplication began. Gametogony could not be differentiated from the first merogony and therefore, these processes are considered equivalent for this species. Micronuclear meronts (= gamonts) were small cells with a relatively large nucleus (Figs. 15, 21). Once multiplication began, it was by binary fission (Fig. 16) and the final products were considered gametes. All stages in his sequence developed in direct contact with the host cell cytoplasm in oenocytes of pupae and young adults. The gametes, slightly larger than the meronts, were pyriform cells with a large nucleus and homogeneous cytoplasm of scattered ribosomes and Golgi in the form of small vesicles (Figs. 17, 22 to 26). Dispersed clumps of chromatin characterized the nuclei which were commonly located at the broad end of the pyriform cell (Figs. 24, 25). A unique feature of the gamete was a projection, in the form of a nipple, located at the anterior end. The projection, for which 


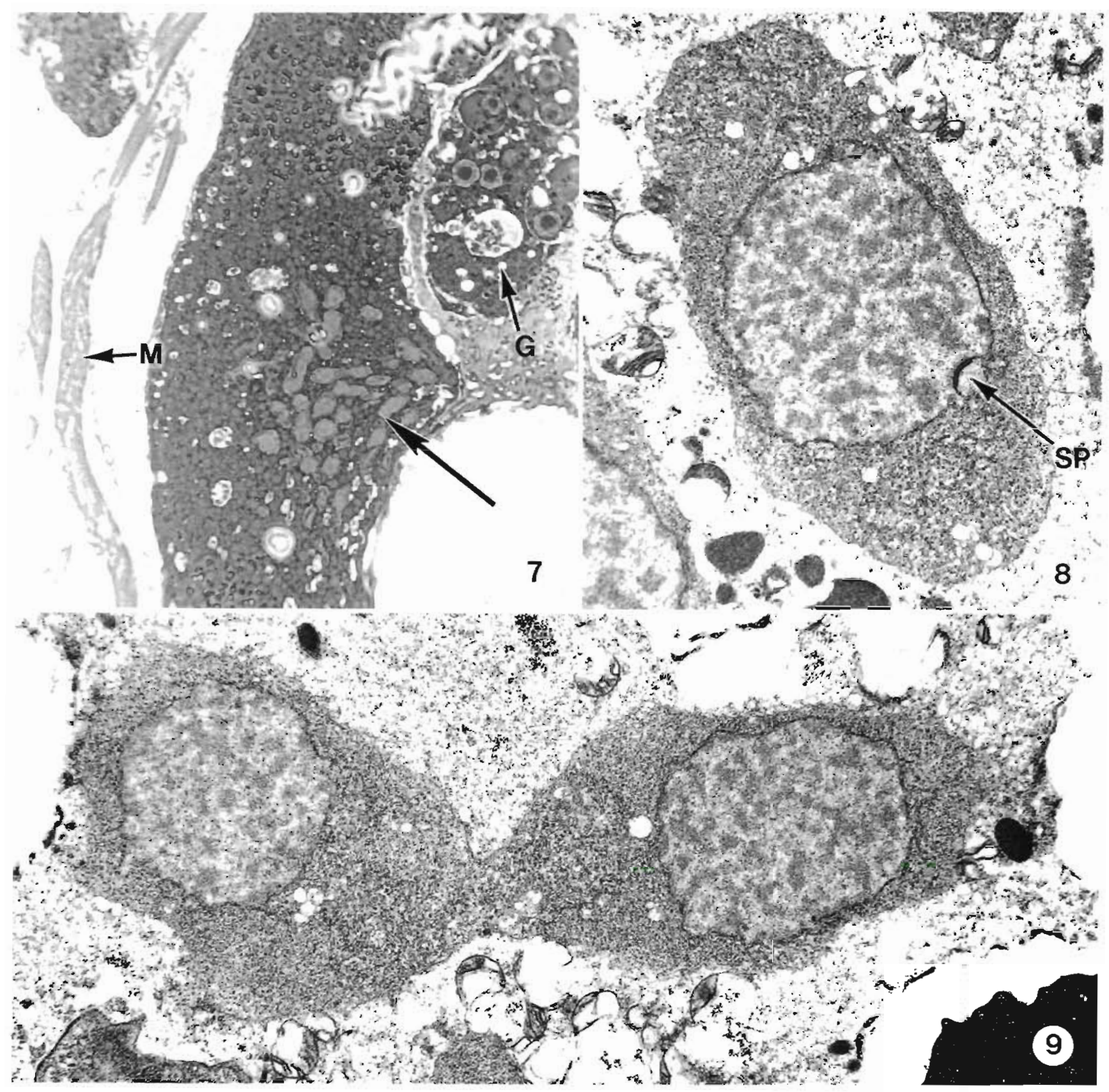

Figs 7 to 9 Amblyospora californica Merogonial stages in the copepod Macrocyclops albidus. Fig. 7. Histological sagittal section of the copepod with infected ovarian tissues (arrow), muscle (M) and gut $(\mathrm{G}), \times 250$. Fig. 8 . Uninucleate meront with a spindle plaque (SP) on the nuclear envelope: $\times 10900$ Fig. 9 . Binary fission of meront; $\times 7500$

the term 'papilla' (= any small nipple-like process or projection, Webster) is suggested, first appeared as a doubling and thickening of the plasmalemma (Fig 23. 23a). These membranes coalesced and developed into the papila (Fig 24, 24a) The anterior end of the gamete was often bent to one side (Fig 24) and some variation in the shape and length of the papilla was noted. The presence of papllae on all pynform gametes was not determined.
Plasmogamy and nuclear association. Gametes came together in parrs, elther by side (Fig. 25) or end to end (Fig. 26), and plasmogamy (cytoplasmic fusion) soon followed (Frgs. 18, 26). This occurred primarily in young adults but sometmes took place in pupae. After plasmogamy, the 2 nuclei (now in a common cytoplasm) migrated towards one another (Fig. 26). These nuclei did not fuse but rather became associated to form a diplokaryon (Fig. 27). The resulting diplokaryotic cells were meronts. 


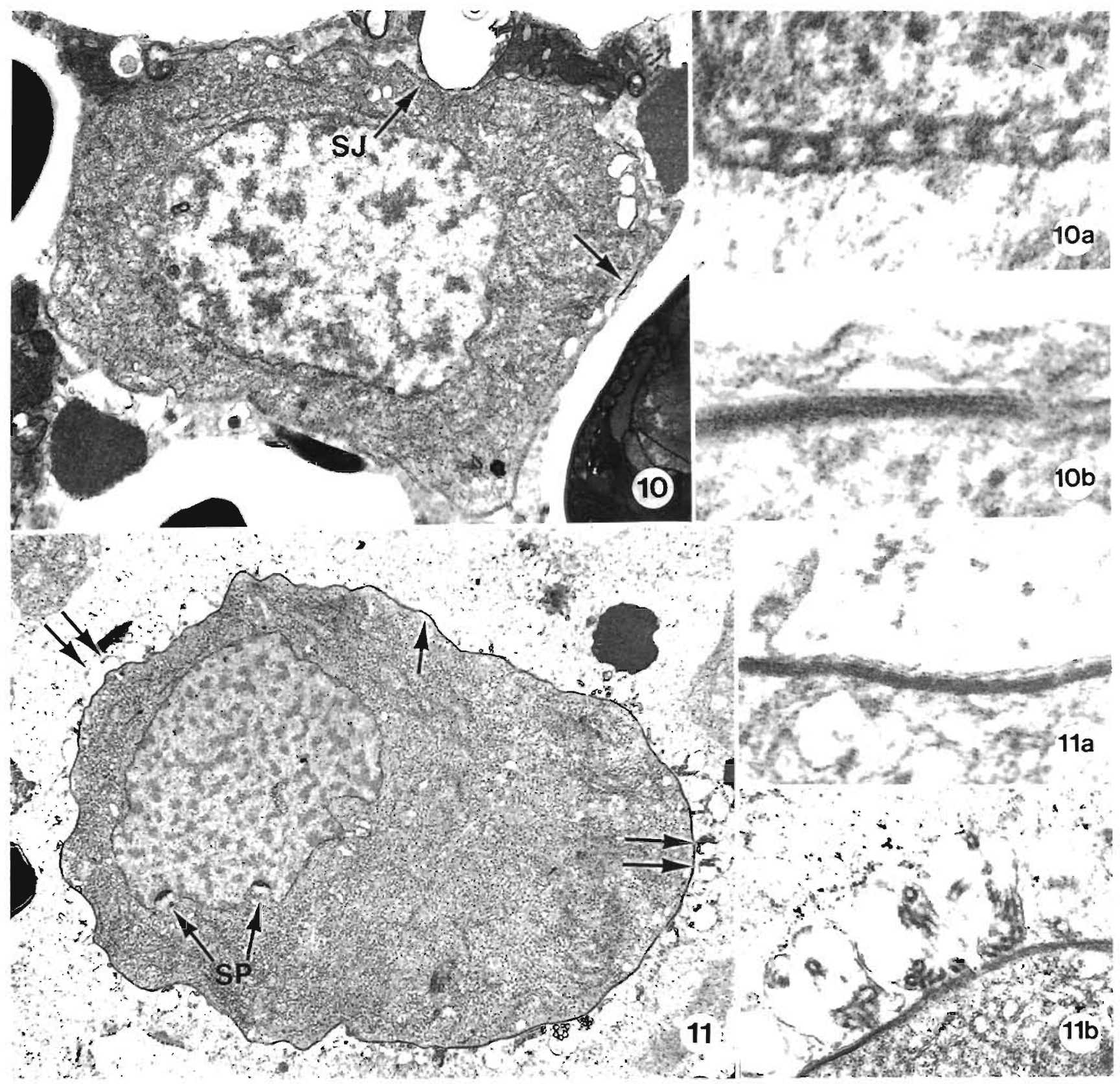

Figs. 10 to 11. Amblyospora californica Merogony to sporogony tiansitional forms in Macrocyclops albidus. Fig. 10. Transitional form demonstrating a septate junction (SJ) and a thickenıng beneath the plasmalemma (arrow), $\times 10900$ Fig. 10a. Enlargement of septate junction in Fig. $10 ; \times 160000$ Fig. 10b. Enlargement of thickening beneath the plasmalemma of Fig $10, \times 125800$ Fig. 11. Uninucleate sporont with doubled spindle plaques (SP) on the nuclear envelope and the beginnings of the interfacial envelope on the plasmalemma; $\times 6000$. Fig. $11 \mathrm{a}$. Enlargement of the delicate membrane that forms external to the plasmalemma from Fig. 11; $\times 65000$. Fig. 11b. Enlargement of blısters contaınıng tubular metabolıc material from Fig 11. $\times 20400$

Second merogony (often called 'macronuclear' merogony). Diplokaryotic meronts divided by binary fission (Fig. 19) and accumulated in oenocytes of the adult. This merogony apparently represented the main multiplicative phase of the developmental sequence.

Sporogony and sporogenesis. Fusiform diplokaryotic stages (Fig. 20) were the final products of the second merogony. They presumably divided once into binucleate sporoblasts (Figs. 20,28). These sporoblasts became the binucleate spores described by previous authors and found to be involved in transovarial transmission (Kellen et al 1967, Chen 1988). Thus, the mosquito in which development occurred, after ingestion of uninucleate spores from the copepod, was a 


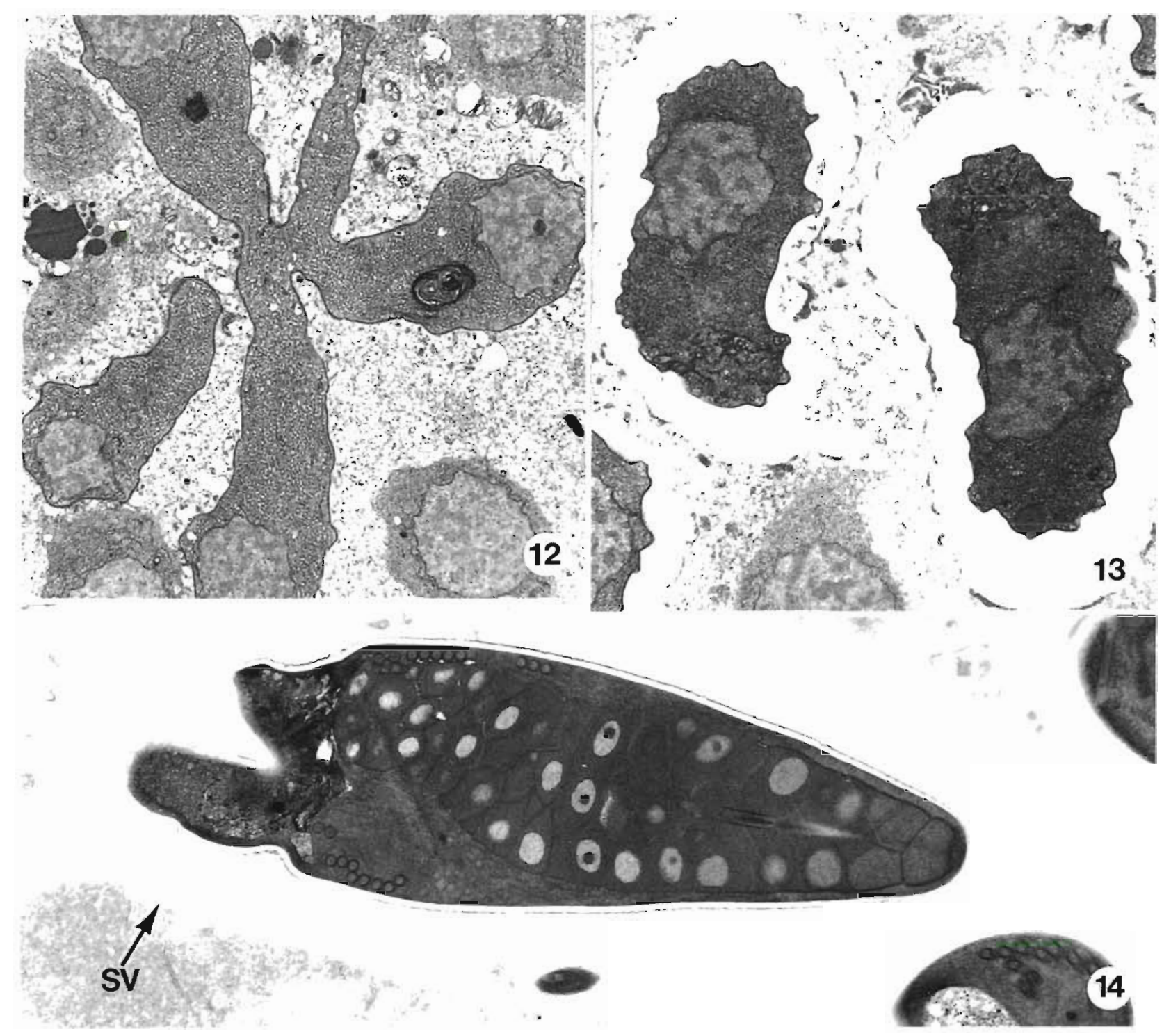

Figs. 12 to 14. Amblyospora californica. Electron micrographs of the sporulation sequence in Macrocyclops albidus. Fig. 12. Sporogonial plasmodium dividing in the form of a rosette; $\times 5100$. Fig. 13 . Two uninucleate sporoblasts, each isolated by an interfacial envelope $; \times 6300$. Fig. 14. Mature spore within a sporophorous vesicle (SV); $\times 10700$

parental generation individual capable of transmitting the infection ovarially to successive filial generations via binucleate spores. Binucleate spores were also formed in male individuals but their role is unknown.

\section{DISCUSSION}

\section{Life cycle of Amblyospora californica}

The present detailed account of 2 spore to spore developmental sequences that result from horizontal transmission to intermediate and definitive hosts of Amblyospora californica supplements and verifies the previously fragmentary knowledge of them, firmly establishing these aspects of the life cycle as essential characters of the species. Now, all the salient features of the life cycle of $A$. californica have apparently been established. By combining published information on other phases of the cycle of this species with the information derived from this study, the complete life cycle of the type species of Amblyospora can be summarized.

Amblyospora californica has 3 sporulation sequences involving 2 host species (Fig. 29). One sporulation sequence is in the parental generation female mosquito. This sequence involves sporogony by binary division of diplokaryotic sporonts and the production of isolated binucleate spores responsible for transovarial 

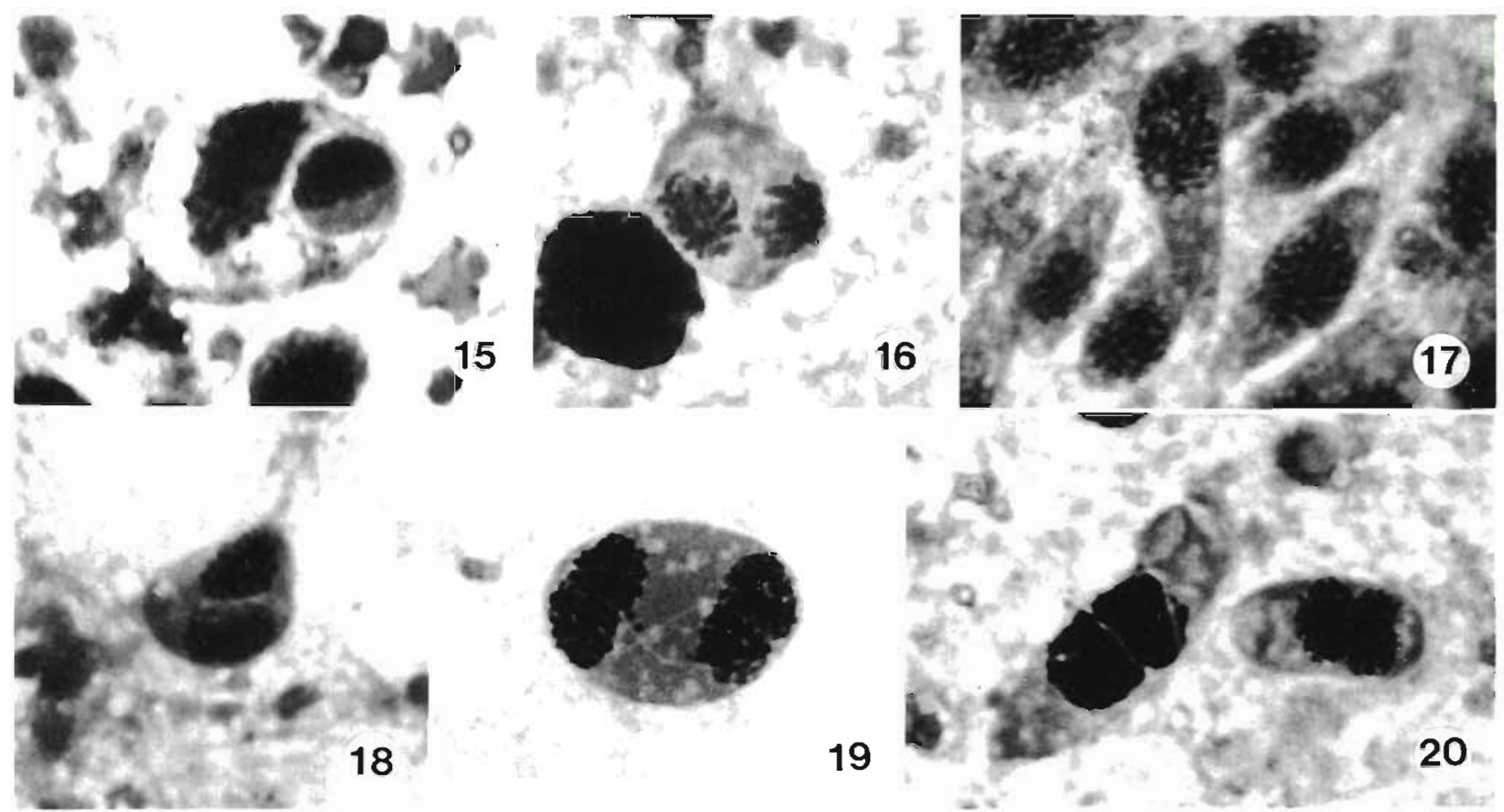

19

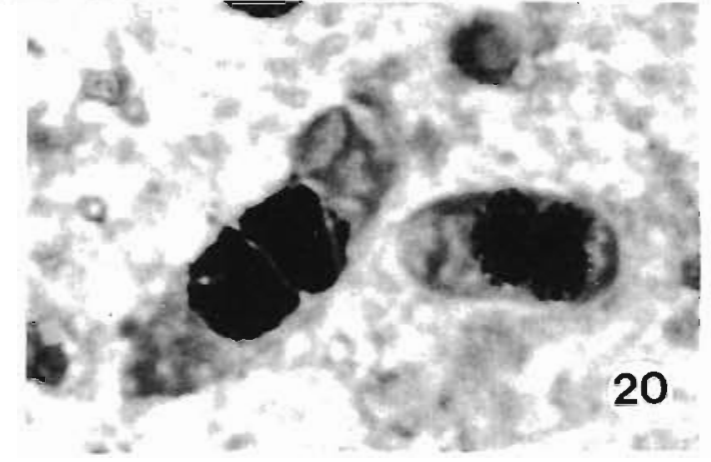

Figs. 15 to 20. Photomicrographs of the developmental sequence of Amblyospora californica in oenocytes of pupae and adults of Culex tarsalis initiated by uninucleate spores formed in Macrocyclops albidus. Giemsa-stained; $\times 2000$. Fig. 15 . Uninucleate stage (gamont) in a host oenocyte. Fig. 16. Uninucleate meront and meront dividing. Fig. 17. Group of gametes. Fig. 18. Plasmogamy of gametes. Fig. 19. Binary fission of diplokaryotic meront. Fig. 20. Binucleate sporont (left) and sporoblast (right)

transmission (Fig. 29, Spore I). This sporulation sequence is arrived at by 2 distinctly different pathways.

Pathway 1 is simple, involving repeated transovarial transmission to and development within female mosquitoes (Kellen \& Wills 1962b). Filial generation females (after transovarial transmission) develop benign oenocytic infections. Diplokaryotic merogony is by binary division and ends with diplokaryotic sporonts in the adult (Kellen et al. 1967).

Pathway 2 is complex involving 2 sporulation sequences and an obligatory intermediate host. The first sequence occurs in the fat body of male larvae as a result of transovarial transmission. This sequence has been described, at least in part, by Kellen \& Lipa (1960), Kudo \& Daniels (1963), Hazard \& Oldacre (1975), Lipa \& Bartkowski (1981), Becnel (1986), and Chen (1988). Some of the details on meiosis must be inferred from studies made on other species, particularly that made by Hazard \& Brookbank (1984). Diplokaryotic merogony occurs by binary division. This is followed by karyogamy and octosporoblastic sporogony that is accompanied by meiosis. The resulting meiospores (Fig. 29, Spore II) are infectious orally to a copepod intermediate host. Sporulation occurs in the ovarian tissues of female copepods, following binary division of uninucleate meronts and disporoblastic (occasionally multisporoblastic) sporogony. The resulting uninucleate spores (Fig. 29, Spore [II) are infectious orally to mosquito larvae where the presporulation sequence involves gametogony and plasmogamy. Nuclear association results in diplokaryotic meronts that divide by binary division producing diplokaryotic sporonts in oenocytes of the adult female mosquito.

Both pathways therefore, serve to maintain Amblyospora californica in the adult female mosquito. Transovarial transmission is apparently a very efficient and safe means of maintaining infections in a mosquito population. It facilitates dispersion to and invasion of new copepod and mosquito populations that would otherwise be inaccessible.

\section{Copepod host and tissue specificity}

Amblyospora californica infects the copepods Macrocyclops albidus and Mesocyclops leukarti. Both of these species are competent to serve as intermediate host for $A$. californica to successfully complete its developmental cycle in Culex tarsalis (Sweeney et al. 1985). Chen (1988) was unable to infect $C$. tarsalis with spores obtained from Acanthocyclops vernalis cultures reportedly infected with $A$. californica. My attempts to infect $A$. vernalis cultures (the intermediate host of 


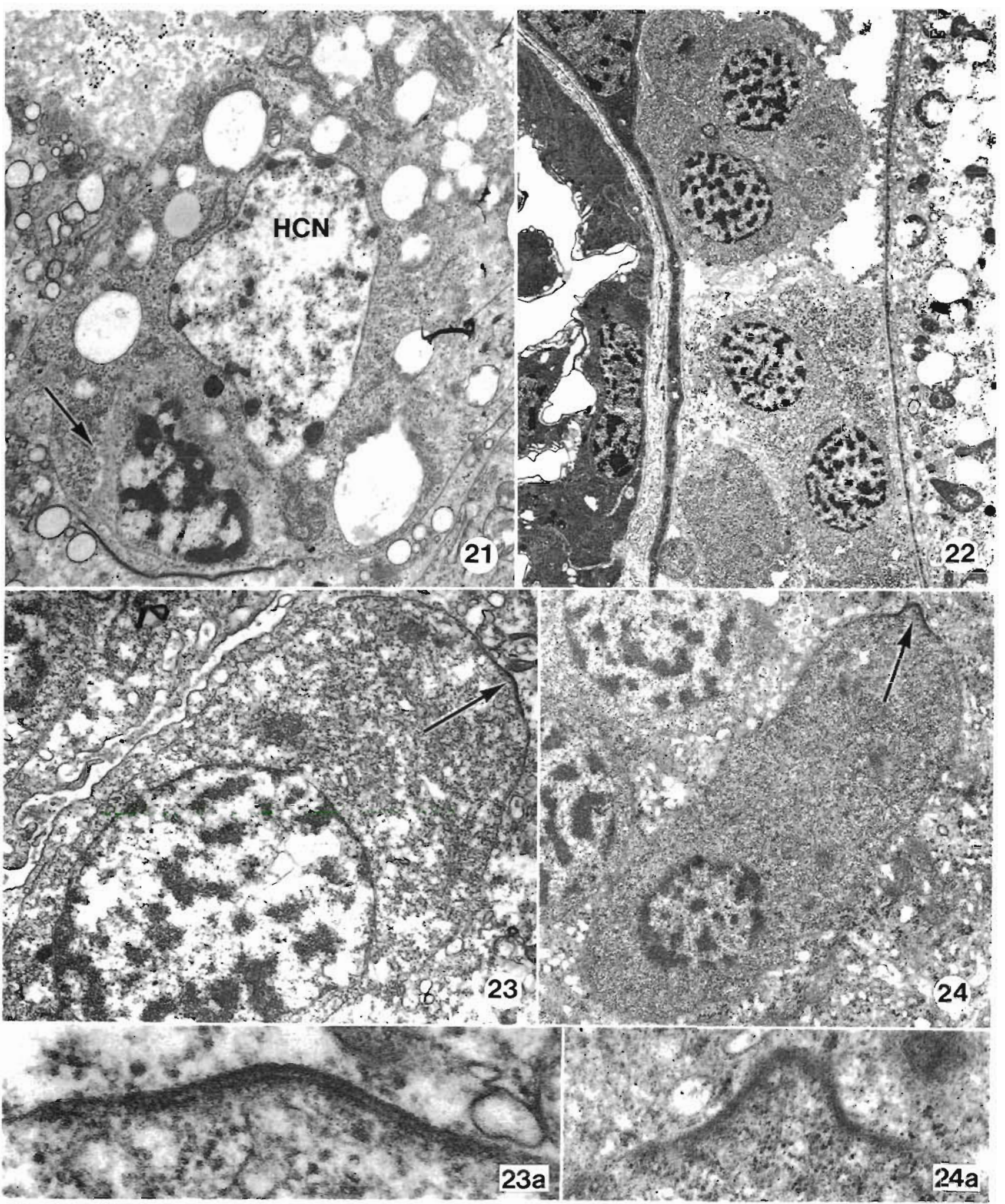

Figs 21 to 24 Electron micrographs of selected developmental stages of Amblyospora callfornica in Culex tarsalis initrated by uninucleate spores formed in Macrocyclops albidus. Fig. 21. Uninucleate stage (gamont) in host cell cytoplasm (arrow) Host cell nucleus $(\mathrm{HCN}) ; \times 8000$. Fig. 22. Gametes in host benocyte with Malpighian tubule to the left and hind gut to the nght, $\times 4000$ Fig. 23. Gamete with the beginnings of a papilla on the apex of the gamete larrow); $\times 14400$. Fig. $23 \mathrm{a}$. Enlargement of the developing papilla in Fig 23; $\times 168000 \mathrm{Fig} .24$. Gamete with a papilla at the apex of the cell (arrow); $\times 10000$. Fig. 24a. Enlargement 


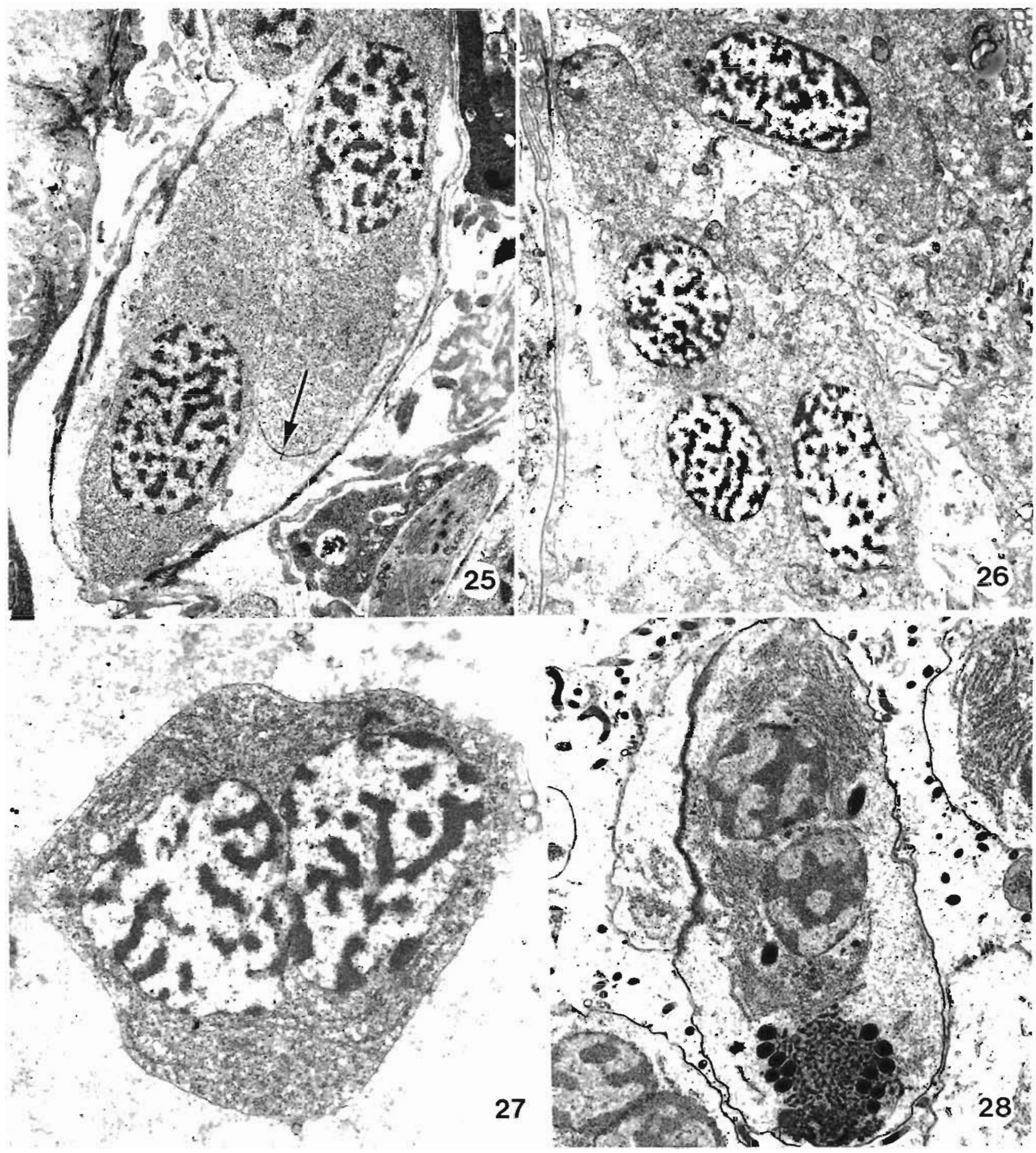

Figs. 25 to 28. Amblyospora californica Electron micrographs of developmental stages in Culex tarsalis initiated by uninucleate spores formed in Macrocyclops albidus Fig. 25. Two gametes prepanng for plasmogamy, note the thickened plasmalemma at the apex of the individual on the right (arrow), $\times 6000$ Fig 26 Two gametes (left) following plasmogamy, the 2 nuclel migratıng towards one another; $\times 6000$. Fig. 27. Newly formed diplokaryotic meront, $\times 6500$. Fig. 28 . Binucleate sporoblast, $\times 9000$

A. connecticus) were unsuccessful. One possible explanation for this discrepancy is that $A$. vernalis may be represented by different forms (Yeatman 1944) not all of which produce spores infectious to $C$. tarsalis. Another is that $A$. vernalis is not a suitable host for A. callfornica. 
The ovarian tissues are the primary sites of infection of Amblyospora californica in copepods. This tissue specificity is also characteristic for $A$. connecticus in the copepod Acanthocyclops vernalis (Andreadis 1988a) and A. dyxenoides in the copepod Mesocyclops albicans (Sweeney et al. 1988, Sweeney et al. 1989). Andreadis (1988b) was also able to infect $A$. vernalis copepodids and because the rate of transmission to the copepodids was one-half that obtained with adult females, he concluded that only female copepodids were susceptible He also reported that infected female copepods do not produce eggs and therefore maintenance in the copepod by vertical transmission seems unlikely. Present results are in agreement with this conclusion. The possibility that horizontal transmission from copepod to copepod occurs has not been addressed.

\section{The septate desmosomes}

Transitional forms were recognized in Amblyospora californica by alterations at the interface between the parasite and the host. The most unusual of these were areas (Fig. 10) similar to septate desmosomes. These are specialized cell junctions that consist of 'septa'

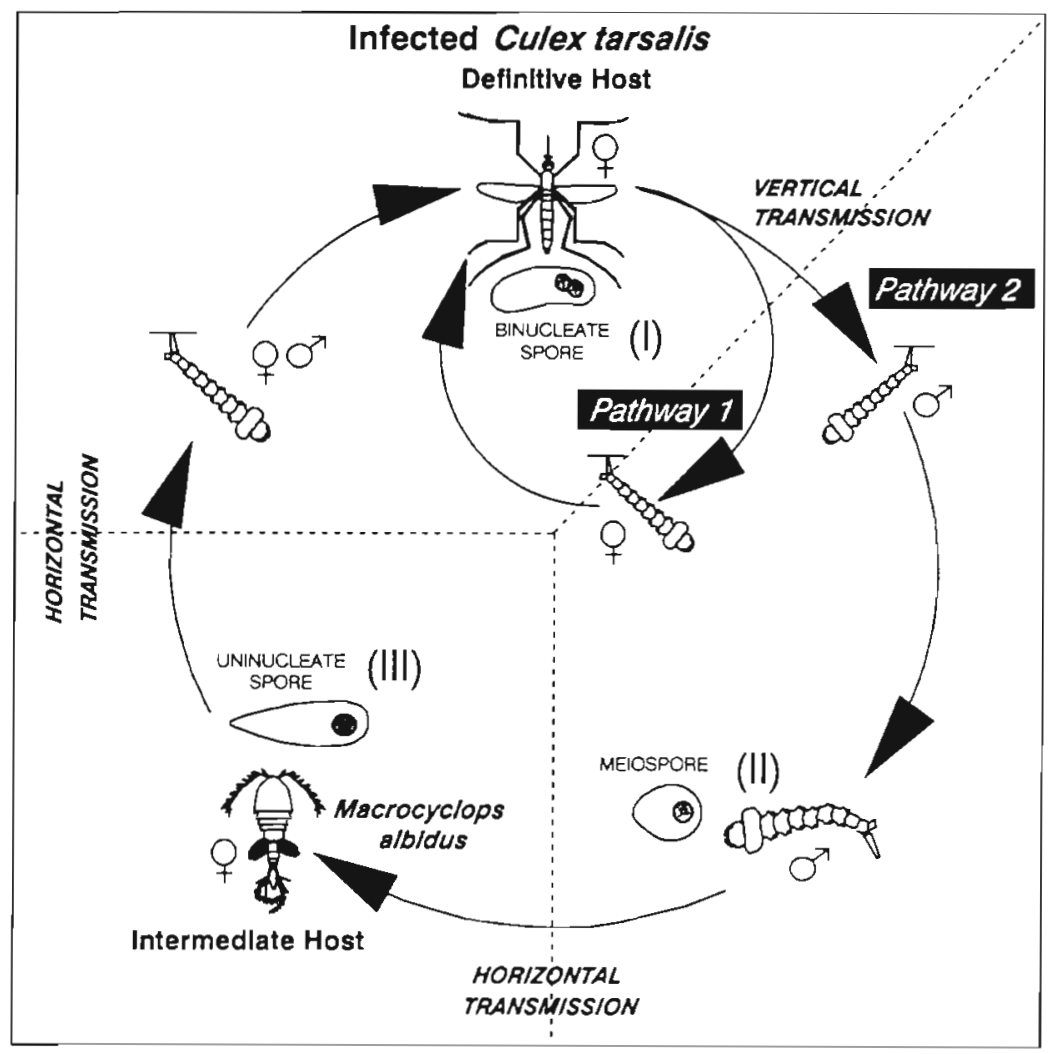

Fig. 29. Life cycle diagram of Amblyospora californica in Culex tarsalis and Macrocyclops albidus spaced 15 to 17 nm apart (Fig. 10a) and are characteristic for and apparently restricted to invertebrates (Wolf 1981). One suggested role in invertebrate tissues is cell to cell adhesion as they are abundant in tissues subjected to shear or stress such as epithelia. Another possible function is intercellular movements of ions and molecules in the salivary glands of Drosophila (Smith 1968). If the specialized interface observed on the transitional cells in Macrocyclops albidus actually represents septate desmosomes, then a special recognition between host cell membranes (endoplasmic reticulum?) and the parasite plasmalemma is indicated. While the occurrence of a special relationship between microsporidia and host membranes (primarily endoplasmic reticulum during sporulation) is widely reported, the formation of cell junctions is not. This represents a new interfacial feature for the microsporidia whose function remains to be determined.

\section{The interfacial envelope in the copepod host}

Sporonts of Amblyospora californica in Macrocyclops albidus form an interfacial envelope by a doubling of the plasmalemma that eventually becomes a delicate monosporophorous vesicle. $A$. connecticus and $A$. dyxenoides are similar to $A$. californica in that spores are individually contained within a delicate sporophorous vesicle (Andreadis 1985, Sweeney et al. 1988). The origin of the sporophorous vesicle for $A$. connecticus is also as a result of a doubled plasmalemma but differs from A. californica in that early sporoblasts (rather than sporonts) apparently give rise to the envelope. A. connecticus also differs by not producing tubular material but only amorphous material within the episporontal space. Details on the origin of the sporophorous vesicle for $A$. dyxenoides are not available.

\section{The papilla on the gamete}

The most significant morphological feature of the gametes in Amblyospora californica is the presence of a papilla on the narrow (anterior) end of the cell. This structure has not previously been reported for Amblyospora but is found on the gametes of Edhazardia aedis (Hazard et al. 1985, Becnel et al. 
1989) and Culicospora magna (Hazard et al. 1985 Becnel et al. 1987). Sweeney et al. (1988) did not study the ultrastructure of the gametes of $A$. dyxenoides, and Andreadis (1988a) was unable to find evidence of papillae on gametes of $A$. connecticus. Additional ultrastructural investigations on the Amblyospora are necessary to determine whether these papillae occur in only certain species or are a common feature of gametes in Amblyospora as well as Culicospora and Edhazardia.

The function of the papilla has not been determined nor is it known to be present on all gametes (i.e. isogametes or anisogametes). The papilla often gives the impression of a probing or seeking nature as indicated in Fig. 24. The thickened plasmalemma at the apex of one of the 2 gametes undergoing plasmogamy (Figs, 25, 26) suggests the presence of a papilla. This structure, found on stages undergoing plasmogamy, suggests a possible role in recognition of the appropriate mating partner and may involve the joining of anisogametes.

\section{The chromosome cycle}

The life cycle diagram implicitly includes the chromosome cycle, which can now be conceptualized in its entirety. The emergence of a genetically new diploid individual (typically the zygote) is the logical starting point of a chromosome cycle that involves sexuality. In the present species the genetically new diploid individual (defined to treat the diplokaryon as a diploid nucleus) is the first diplokaryotic cell in the cycle. That individual is the first 'copula' - a term introduced by Debaisieux (1928) and adopted by Becnel et al. (1987) - which arises in the parental generation mosquito larva by cytoplasmic fusion (plasmogamy) of 2 gametes and subsequent association of the nuclei to form a diplokaryon. All diploid individuals in the cycle constitute the diplophase (dihaplophase) part of the cycle. All diplophase individuals, the copula and its direct descendants without sexual intervention, are genetically identical cells; in this way they are comparable to the diploid cells that constitute the soma in familiar animal life cycles. With meiosis in the filial generation male larva the diplophase ends and the haplophase begins. All the uninucleate individuals in the life cycle are haploid due to meiosis and are genetically different from one another due to the recombination of genes. The haplophase ends with cytoplasmic fusion of gametes and association of nuclei. These events produce a genetically new diploid individual, the copula or first meront, in a new parental generation female mosquito and it is the initial stage of a new life cycle.

\section{Comparison with other Amblyospora spp.}

With the complete life cycles of Amblyospora californica, $A$. connecticus and $A$. dyxenoides established, a common theme has emerged with only minor variations. It is now apparent that an Amblyospora species can form 2 distinct spore types in one host group and a third spore type in a second host group. Comparisons of the nuclear cycles as well as the morphological and functional features of the various stages for these 3 Amblyospora spp. have shown them to be virtually indistinguishable (Andreadis 1985 , 1988a, b, 1990, Sweeney et al. 1985, 1988). However, transmission testing indicates that each species may be specific for its respective mosquito host. Andreadis (1989) infected 4 alternate mosquito hosts with $A$. connecticus, but it did not complete its life cycle via transovarial transmission, indicating a high degree of specificity for the natural host, Aedes cantator. His attempts to infect larval Culex tarsalis with $A$. connecticus via spores produced in the copepod $A$. vernalis were unsuccessful. Sweeney et al. (1990) clearly demonstrated with transmission testing that $A$. indicola and $A$. dyxenoides are distinct species, a conclusion that could not be inferred by comparing their development and gross morphologies (size and shape of spores). Although the reasons for this specificity are unclear, it seems likely to be related to specific biochemical and biophysical conditions found in the hosts which have resulted in only subtle morphological changes in the parasites.

\section{Taxonomic implications}

There is now a rather clear understanding of all the main features of the complex microsporidian life cycles involving spores of 3 morphological types and occurring in Amblyospora californica, the type species. This establishes the fact that similar life cycles recently demonstrated for both $A$. connecticus and $A$. dyxenoides are characteristic for the genus. The same type of life cycle was recently demonstrated by Avery \& Undeen (1990) for Parathelohania anophelis, unfortunately, not the type species. This information can help researchers to investigate and understand life cycles of other species, most of which are poorly known. A better understanding of the various life cycles of other species, especially the types, is essential for formulating the basis of a complete and rational classification of the microsporidia. A particularly pertinent problem is to acquire sufficient information to differentiate most of the other taxa in the very large and diverse group of microsporidia that share with Amblyospora a 'Thelohania-like' sporulation sequence. 
Acknowledgements. I thank Ms M. Johnson for excellent technical assistance. I also thank Drs V. Sprague, A. H. Undeen, W. M. Brooks, and T. G. Andreadis for critical review of the manuscript. Special thanks go to Mr T Fukuda and the late E. I. Hazard for therr support and assistance during the course of this project

\section{LITERATURE CITED}

Andreadis, T G. (1985). Experimental transmission of a microsporidian pathogen from mosquito to an alternate copepod host. Proc. natn. Acad. Sci. U.S.A. 82: 5574-5577

Andreadis, T. G. (1988a). Amblyospora connecticus sp. nov. (Microsporida: Amblyosporidae): horizontal transmission studies in the mosquito Aedes cantator and formal description. J. Invertebr. Pathol. 52. 90-101

Andreadis, T. G. (1988b). Comparative susceptibility of the copepod Acanthocyclops vernalis to a microsporidian parasite, Amblyospora connecticus, from the mosquito Aedes cantator. J. Invertebr. Pathol. 52: 73-77

Andreadis, T. G. (1989). Host specificity of Amblyospora connecticus, a polymorphic microsporidian parasite of Aedes cantator. J. med. Ent. 26: 140-145

Andreadis, T. G. (1990). Epizootiology of Amblyospora connecticus (Microspora) in field populations of the saltmarsh mosquito, Aedes cantator, and the cyclopoid copepod Acanthocyclops vernalis. J. Protozool. 37: 174-182

Andreadis, T G., Hall, D. W. (1979). Development, ultrastructure, and mode of transmission of Amblyospora sp. (Microspora) in the mosquito. J. Protozool. 26: 444-452

Avery, S. W., Undeen, A. H. (1990). Horizontal transmission of Parathelohania anophelis to the copepod Microcyclops varicans and the mosquito Anopheles quadrimaculatus. J. Invertebr. Pathol. 56: 98-105

Becnel, J. J. (1986). Microsporidian sexuality in culicine mosquitoes. In: Sampson, R. A., Vlak, J. M., Peters, D. (eds.) Fundamental and applied aspects of invertebrate pathology. IV Internat. Colloq. Invertebr Pathol., Velkhoven, Wageningen, The Netherlands. p. 331-334

Becnel, J. J., Hazard, E. I., Fukuda, T., Sprague, V. (1987). Life cycle of Culicospora magna (Kudo, 1920) (Microsporida, Culicosporidae) in Culex restuans Theobold with special reference to sexuality. J. Protozool. 34: 313-322

Becnel, J. J., Sprague, V., Fukuda, T., Hazard, E. I. (1989). Development of Edhazardia aedis (Kudo, 1930) n. gen., n. comb. (Microspordda: Amblyosporidae) in the mosquito Aedes aegypti (L.) (Diptera: Culicidae). J Protozool. 36 $119-130$

Debaisieux, P. (1928). Etudes cytologiques sur quelques Microsporidies. Cellule 38: 389-450

Chen, W. J. (1988). Development and fine structure of Amblyospora californica in the mosquito Culex tarsalis and an. alternate copepod host Acanthocyclops vernalis. Doctoral dissertation, University of California, Los Angeles

Hazard, E I., Andreadis, T. G., Joslyn, D. J., Ellis, E. A. (1979) Meiosis and its implication in the life cycles of Amblyospora and Parathelohania (Microspora). J. Parasitol. 65 $117-122$

Hazard, E. I., Brookbank, J. W (1984). Karyogamy and meiosis in Amblyospora sp. (Microspora) in the mosquito Culex

Responsible Subject Editor: J. E. Stewart, Dartmouth, N.S., Canada salinarius. J. Invertebr. Pathol. 44:3-11

Hazard, E. I., Fukuda, T., Becnel, J. J (1984). Life cycle of Culicosporella lunata (Hazard \& Savage, 1970) Weiser, 1977 (Microspora) as revealed in the light microscope with a redescription of the genus and species. J. Protozool. 31 385-391

Hazard, E. I., Fukuda, T., Becnel, J. J. (1985). Gametogenesis and plasmogamy in certain species of Microspora. J. Invertebr. Pathol. 46: 63-69

Hazard, E. I., Oldacre, S. W. (1975). Revision of Microsporidia (Protozoa) close to Thelohania, with descriptions of one new family, eight new genera and thirteen new species. U.S. Dept. Agric. Tech. Bull. 1530

Hazard, E. I., Weiser, J. (1968). Spores of Thelohania in adult female Anopheles: development and transovarial transmission, and redescriptions $T$ legeri Hesse and $T$. obesa Kudo. J. Protozool. 15: 817-823

Kellen, W. R., Lipa, J. J (1960). Thelohania californica n. sp. a microsporidian parasite of Culex tarsalis Coquillet. J. Invertebr. Pathol. 2: 1-12

Kellen, W. R., Wills, W. (1962a). New Thelohania from California mosquitoes (Nosematidae: Microsporidia). J. Insect Pathol 4: 41-56

Kellen, W. R., Wills, W. (1962b). The transovarian transmission of Thelohania californica Kellen and Lipa in Culex tarsalis Coquillett. J. Insect Pathol. 4: 321-326

Kellen, W. R., Clark, T. B., Lindegren, J. E. (1967). Two previously undescribed Nosema from mosquitoes of California (Nosematidae: Microsporidia). J lnvertebr. Pathol. 9: 19-25

Kudo, R. R., Daniels, E. W. (1963). An electron microscope study of the spore of a microsporidian. Thelohania californica. J. Protozool. 10: 112-120

Lipa, J. J., Bartkowski, J. (1981). Light and electron microscope study of Amblyospora (Thelohania) californica (Kellen and Lipa) (Microsporidia) in larvae of Culex tarsalis Coq. (Culicidae). Acta Protozool 20: 209-213

Smith, D. S. (1968). Insect cells, their structure and function. Oliver and Boyd Publishers, Edinburgh

Sweeney, A. W., Graham, M. F. Hazard, E. I. (1985). Intermediate host for an Amblyospora sp. (Microspora) infecting the mosquito Culex annulirostris. J. Invertebr. Pathol 46: $98-102$

Sweeney, A. W., Graham, M. F., Hazard, E. I. (1988). Life cycle of Amblyospora dyxenoides sp. nov. in the mosquito Culex annulirostris and the copepod Mesocyclops albicans. J. Invertebr. Pathol. 51: 46-57

Sweeney, A. W., Doggett, S. L., Gullick, G. (1989). Bioassay experiments on the dose response of Mesocyclops sp. copepods to meiospores of Amblyospora dyxenoides produced in Culex annulirostris mosquito larvae. J. Invertebr. Pathol. 53: 118-120

Sweeney, A. W., Doggett, S. L., Piper, R. G. (1990). Host specificity studies of Amblyospora indicola and Amblyospora dyxenordes (Microspora: Amblyosporidae) in mosquitoes and copepods. J. Invertebr. Pathol. 56: 415-418

Wolf, S. L. (1981). Biology of the cell. Wadsworth Publishing Company, Belmont, California

Yeatman, H. C. (1944). American cyclopoid copepods of the viridis-vernalis group (including a description of Cyclops carolinianus n. sp.). Am. Midl. Nat. 32: 1-90

Manuscript first received: September 5, 1991

Revised version accepted: February 20, 1992 